\title{
Separation, purification, and identification of flagellin, and preparation of its antisera
}

\author{
M.D. Hu ${ }^{1}$, G.S. Wang ${ }^{1}$, J. Xu' ${ }^{1}$, W. Yao ${ }^{1}$, B.F. He ${ }^{1}$, Y. Yang ${ }^{1}$, M. Mao ${ }^{2}$, \\ Q. Wang ${ }^{3}$ and J.C. Xu ${ }^{1}$ \\ ${ }^{1}$ Department of Respiratory Medicine, Respiratory Research Institute, \\ The Second Affiliated Hospital, Third Military Medical University, \\ Chongqing, China \\ ${ }^{2}$ Department of Respiratory Medicine, The 324th PLA Hospital, \\ Chongqing, China \\ ${ }^{3}$ Department of Cardiology, The 59th PLA Hospital, \\ Kaiyuan, Yunnan, China \\ Corresponding author: J.C. Xu \\ E-mail: jianchengxucn@yeah.net
}

Genet. Mol. Res. 13 (4): 9161-9170 (2014)

Received May 23, 2014

Accepted October 30, 2014

Published November 7, 2014

DOI http://dx.doi.org/10.4238/2014.November.7.3

\begin{abstract}
The aim of this study was to separate, purify, and identify Salmonella paratyphi A flagellin, and to prepare its antisera. Primary flagellin was isolated from $S$. paratyphi A using the acid lysis method. The flagellin was purified with weak anion exchange chromatography and the protein was identified with sodium dodecyl sulfate-polyacrylamide gel electrophoresis (SDS-PAGE), Western blot, and negative staining with phosphotungstic acid with scanning electron microscopy (SEM). The production of the obtained flagellin was then quantified. New Zealand white rabbits were then immunized with the isolated flagellin, the presence of serum anti-flagellin antibodies was assessed with the immunoblot test, and its potency was determined with the double immunodiffusion test. The results of SDS-PAGE showed that the molecular weight (m.w.) of the purified flagellin was $52 \times 10^{3}$. The immunoblot test also showed a band at $52 \times 10^{3} \mathrm{~m} . \mathrm{w}$. The SEM results
\end{abstract}


showed that the flagellin was filamentous. These three results showed that the protein was homogeneous. The protein quantification analysis found that $4.8 \pm 0.5 \mathrm{mg}$ flagellin could be extracted per $1 \mathrm{~g}$ wet weight bacteria. The titer of the anti-flagellin antiserum was 1:64. Through this method, we obtained high productions of flagellin, which could be easily purified, identified, and prepared into high titer antiserum.

Key words: Salmonella paratyphi A flagellin; Purification; Antisera

\section{INTRODUCTION}

Sepsis is one of the major causes of acute lung injury (ALI)/acute respiratory distress syndrome (ARDS) (Michalska et al., 2009; Rodríguez-Moyado, 2011; Parsons et al., 2011; Dhokarh et al., 2012). Usually, sepsis refers to the release of lipopolysaccharides (LPS) by bacteria resulting in ALI or even ARDS (Sadowitz et al., 2011). In recent years, some studies have reported that in addition to sepsis, the LPS outer flagellin is also an important factor for inducing ALI/ARDS (Faezi et al., 2011; Zhang et al., 2011). Commercial kits are usually used to verify the role of flagellin in ALI/ARDS, which is a convenient but expensive method. Homemade flagellin could greatly reduce these costs. Flagellin separation and purification protocols have been reported (Fey and Wetzstein, 1975), including expanding the culture of bacteria, collecting the bacteria, detaching flagellin from the thallus using different methods, and purifying. However, the separation process may bring forth other proteins due to the medium or due to released proteins during bacterium rupturing, which can partially denature the flagellin. These potential complications make purification a challenge, and even make it impossible to obtain purified flagellin under some circumstances.

In order to improve the yield of the bacteria while simultaneously maintaining its stable physicochemical properties, we improved the medium and the lysis of bacteria using a simple method. The high molecular weight proteins were substituted by amino acids, and the flagellin was detached from the thallus under different $\mathrm{pH}$ conditions. This process is expected to increase the production of flagellin and make it easier to purify and identify, which will provide the basis for the preparation of its antiserum.

\section{MATERIAL AND METHODS}

The following reagents were used: broth (homemade), anti-Salmonella typhi flagellin monoclonal antibody (Inotek Pharmaceuticals, Zhengzhou Biossay Bioengineering), horseradish peroxidase (HRP)-conjugated goat anti-mouse IgG antibody (Zhongshan), concentrated DAB-colored solution (Zhongshan), nitrocellulose membrane (Roche), Coomassie blue R250 (China), and a total protein assay kit (Nanjing Jiancheng Bioengineering Institute); all other ordinary reagents were of analytical grade. S. paratyphi A was provided by the clinical laboratory bacteriology rooms of our hospital, and was generated from the standard strain ACTT 25922 (provided by the Clinical Laboratory Center of the Ministry of Health). The following instruments were used: vertical protein electrophoresis groove (Pow2erPAC300, Bio2Rad; USA), gel imaging density analysis system and density analysis software Quantity One (Bio2Rad, USA), electric transfer instrument (DYY III406, Beijing 
Liuyi Instrument Factory), high-performance liquid layer analysis system (AKTA Explorer, Pharmacia Co.; Sweden); desalting column (Hiprep26P10 desalting, Pharmacia Co.; Sweden), weak anion exchange chromatography column (Hiprep 16P10 DEAE FF, Pharmacia, Inc.), and a scanning electron microscope (EM300, Phillips).

\section{Separation of crude flagellin}

\section{Broth preparation}

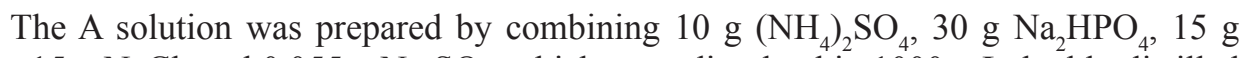
$\mathrm{KH}_{2} \mathrm{PO}_{4}, 15 \mathrm{~g} \mathrm{NaCl}$, and $0.055 \mathrm{~g} \mathrm{Na}_{2} \mathrm{SO}_{4}$, which were dissolved in $1000 \mathrm{~mL}$ double-distilled water, and the $\mathrm{pH}$ was adjusted to 7.2 using $1 \mathrm{M} \mathrm{NaOH}$. The B solution was prepared by combining $0.25 \mathrm{~g} \mathrm{MgCl}_{2}, 0.013 \mathrm{~g} \mathrm{CaCl}_{2}, 0.0006 \mathrm{~g} \mathrm{FeCl}_{3} \cdot 7 \mathrm{H}_{2} \mathrm{O}, 0.125 \mathrm{~g}$ yeast extract, and $0.31 \mathrm{~g}$ DL-tryptophan, L-histidine, L-proline, L-threonine, L-arginine, DL- $\alpha$-alanine, L-methionine, which were dissolved in $1000 \mathrm{~mL}$ double-distilled water and the $\mathrm{pH}$ was adjusted to $7.2 \mathrm{using}$ $1 \mathrm{M} \mathrm{HCl}$. The A and B solutions were high-pressure steam sterilized, respectively, and mixed together in $25 \%$ glucose solution at a 10:40:1 ratio.

\section{Bacterial culture and the preliminary separation of flagellin}

S. paratyphi A strains were vaccinated to blood agar at $37^{\circ} \pm 2^{\circ} \mathrm{C}$ and cultured for 16-18 $\mathrm{h}$ to ensure the bacterial resuscitation. A single colony was selected and inoculated in $10 \mathrm{~mL}$ homemade medium. The medium was placed on a constant temperature shaking table at $100 \mathrm{rpm}$ at $37^{\circ} \pm 2^{\circ} \mathrm{C}$ and incubated for $16-18 \mathrm{~h}$. The colony was then transplanted to 500 $\mathrm{mL}$ homemade broth, incubated under the same conditions for $16-18 \mathrm{~h}$, centrifuged at $4^{\circ} \mathrm{C}$ at $1500 \mathrm{rpm}$ for $30 \mathrm{~min}$, and the supernatant was removed to collect the bacteria. The bacteria were dissolved in $5 \mathrm{~mL}$ saline and the $\mathrm{pH}$ was adjusted to 2.0 with $1 \mathrm{M} \mathrm{HCl}$. The suspension was concentrated at $4^{\circ} \mathrm{C}$ at $1500 \mathrm{rpm}$ for $30 \mathrm{~min}$ and the supernatant was removed to collect the bacteria. The bacteria were dissolved in $5 \mathrm{~mL}$ saline and the $\mathrm{pH}$ was adjusted to 2.0 with $1 \mathrm{M} \mathrm{HCl}$. The suspension was continued at $4^{\circ} \mathrm{C}$ at $1500 \mathrm{rpm}$ for $30 \mathrm{~min}$ and the supernatant was removed to collect the bacteria. The bacteria were dissolved in $5 \mathrm{~mL}$ saline and the $\mathrm{pH}$ was adjusted to 2.0 with $1 \mathrm{M} \mathrm{HCl}$. The suspension was continuously stirred for $30 \mathrm{~min}$ at room temperature and the $\mathrm{pH}$ was maintained at 2.0. The suspension was then centrifuged at $4{ }^{\circ} \mathrm{C}$ at $1500 \mathrm{rpm}$ for $30 \mathrm{~min}$, the deposit was discarded, the supernatant was collected, the $\mathrm{pH}$ was adjusted to 7.2 using $1 \mathrm{M} \mathrm{NaOH}$, and $2.67 \mathrm{M}\left(\mathrm{NH}_{4}\right)_{2} \mathrm{SO}_{4}$ were slowly added and the solution was continuously stirred. The liquid mixture was incubated overnight at $4{ }^{\circ} \mathrm{C}$, and then centrifuged at $4^{\circ} \mathrm{C}$ at $30,000 \mathrm{rpm}$ for $15 \mathrm{~min}$. The supernatant was removed, and the deposit was collected, dissolved in $5 \mathrm{~mL}$ double distilled water, and preserved at $4^{\circ} \mathrm{C}$.

The crude flagellin was subjected to sodium dodecyl sulfate-polyacrylamide gel electrophoresis (SDS-PAGE) with 4\% stacking gel (upper gel) and 1\% separating gel (lower gel) as the separating carriers (see Sambrook and Russell, 1989 for details).

\section{Purification of flagellin}

For desalination, $20 \mathrm{mM}$ phosphate-buffered saline (PBS) were used as the balance 
and elution buffer, and the $\mathrm{pH}$ was adjusted to 6.0 with $\mathrm{HCl}$. The desalting Hiprep 26/10 column ( $53 \mathrm{~mL}$ column bed volume) was connected to the AKTA Explorer, and the desalting column was balanced with equilibration buffer at a $5 \mathrm{~mL} / \mathrm{min}$ flow rate. Two bed column volumes $\left(10^{6} \mathrm{~mL}\right)$ were balanced and the solution was monitored at UV 280, 254, and $215 \mathrm{~nm}$ until the three curves were horizontal. The sample volume was $10 \%$ of the bed volume, and $5 \mathrm{~mL}$ crude flagellin was injected to a $50 \mathrm{~mL}$ sample loop at a $3 \mathrm{~mL} / \mathrm{min}$ flow rate with a syringe. The solution was eluted with elution buffer at a $5-\mathrm{mL} / \mathrm{min}$ flow rate. The eluted protein was collected at the first peak, and $2 \mathrm{~mL}$ protein was placed in each tube. After the salt peak outflow, the sample was run a second time until the three curves were horizontal, and this process was repeated three times until all of the crude flagellin solution was desalinated. The desalination product was stored at $4^{\circ} \mathrm{C}$.

For weak anion exchange chromatography, $20 \mathrm{mM}$ PBS were used as the starting buffer, the $\mathrm{pH}$ was adjusted to 6.0 with $\mathrm{HCl}$, and $20 \mathrm{mM}$ PBS were used as the elution buffer with the $\mathrm{pH}$ adjusted to 6.0 with $1 \mathrm{M} \mathrm{NaCl}$. The Hiprep16/10 DEAE FF weak anion exchange chromatographer was connected to the AKTA Explorer, rinsed with $100 \mathrm{~mL}$ elution buffer, and then balanced with $100 \mathrm{~mL}$ starting buffer at a $5-\mathrm{mL} / \mathrm{min}$ flow rate. The solution was monitored at UV 280, 254, and $215 \mathrm{~nm}$ until the three curves were horizontal. The desalination product was injected to a $50-\mathrm{mL}$ sample loop at a $5-\mathrm{mL} / \mathrm{min}$ flow rate. After outflow of all the peaks, the liquid was balanced with starting buffer until the monitoring curve was horizontal. Salinity gradient elution was performed by adding less than $200 \mathrm{~mL}$ elution buffer at a $5-\mathrm{mL} / \mathrm{min}$ flow rate to increase the $\mathrm{NaCl}$ concentration from 0 to $1 \mathrm{M}$. Two milliliters eluted protein was placed into heat source-removed collection tubes and stored at $-70^{\circ} \mathrm{C}$ after freeze-drying.

\section{Identification of purified flagellin}

Crude flagellin was subjected to SDS-PAGE on 4\% stacking gel (upper gel) and 1\% separating gel (lower gel) as the separating carriers (Sambrook and Russell, 1989; Rodríguez-Moyado, 2011). For Western blot (Sambrook and Russell, 1989; Rodríguez-Moyado, 2011) analysis, purified flagellin was electrophoresed and transferred onto the nitrocellulose membrane. The membrane was blocked for $4 \mathrm{~h}$ at room temperature with $1 \%$ non-fat dry milk, and then incubated with 1:1000 mouse anti-Munich typhoid Salmonella flagellin monoclonal antibody overnight at room temperature. The membrane was washed three times with Tris-buffered saline with Tween (TBST) for 10 min each time, and was then incubated with 1:1000 HRP-conjugated goat anti-mouse IgG antibody for $3 \mathrm{~h}$ at room temperature. The membrane was washed three times with TBST, stained with DAB for $10 \mathrm{~min}$, and the results were observed.

For negative staining, the lyophilized flagellin was dissolved in $2 \mathrm{~mL}$ double-distilled water, and then 1-drop flagellin solution was added to the copper mesh and was let stand for $10 \mathrm{~min}$. After the protein was partially homogeneously deposited onto the copper mesh, the copper mesh was transferred to the wax board, 1 drop $2 \%$ phosphotungstic acid was added, and the solution was maintained at $\mathrm{pH} 7.41$ with $1 \mathrm{M} \mathrm{KOH}$. The flagellin was stained for $5 \mathrm{~min}$ and the copper mesh was removed. The morphology of the negatively stained flagellin was recorded under scanning electron microscopy (SEM). The quantification of flagellin was made using Coomassie blue assay. 


\section{Preparation, identification, and titer determination of rabbit anti-flagellin antiserum}

Following Tang et al. (2011), we added $3 \mathrm{~mL} 0.16 \mathrm{mg} / \mathrm{mL}$ prepared flagellin to $3 \mathrm{~mL}$ PBS buffer and $3 \mathrm{~mL}$ complete Freund's adjuvant. The mixture was shaken to achieve complete emulsification. One-milliliter mixture was multi-point subcutaneously injected in rabbits. After 2 weeks, incomplete Freund's adjuvant and half dose flagellin were used for repeated injections. During the immunization, the production of antibody was examined in the marginal ear vein. If the titer $\geq 1: 16$ before one week, the immunization was strengthened. Rabbits were killed by bloodletting from the carotid artery, and the serum was separated from the blood.

Western blot was used to identify the rabbit anti-flagellin antibodies in serum (Sambrook and Russell, 1989). Purified flagellin was electrophoresed and transferred onto the nitrocellulose membrane. The membrane was blocked for $4 \mathrm{~h}$ at room temperature with $1 \%$ non-fat dry milk, and then incubated with 1:10 flagellin antiserum overnight at room temperature. The membrane was washed three times with TBST for 10 min each time, and incubated with 1:1000 HRP-conjugated goat anti-rabbit IgG antibody for $3 \mathrm{~h}$ at room temperature. The membrane was washed three times with TBST, stained with DAB for $10 \mathrm{~min}$, and the results were observed.

The antiserum titer was examined by using the double immune diffusion method (Sambrook and Russell, 1989), and then preserved at $-70^{\circ} \mathrm{C}$.

\section{RESULTS}

\section{Extraction and detection of crude flagellin}

S. paratyphi A was amplified, cultured in homemade liquid medium, and collected. We obtained flagellin-enriched solutions in different $\mathrm{pH}$ environments under different centrifugal speeds. Crude flagellin was obtained through the $\left(\mathrm{NH}_{4}\right)_{2} \mathrm{SO}_{4}$ salting-out method.

The gel imaging system analysis by SDS-PAGE showed that the protein bar band was mainly located at the $52 \times 10^{3}$ molecular weight (m.w.) position, which confirmed that flagellin was indeed the structural protein of the filamentous portion of the Salmonella flagella (i.e., $\mathrm{H}$ antigens), which is $40-60 \times 10^{3}$ m.w. (Liaudet et al., 2003), indicating the successful extraction of the crude flagellin (Figure 1).

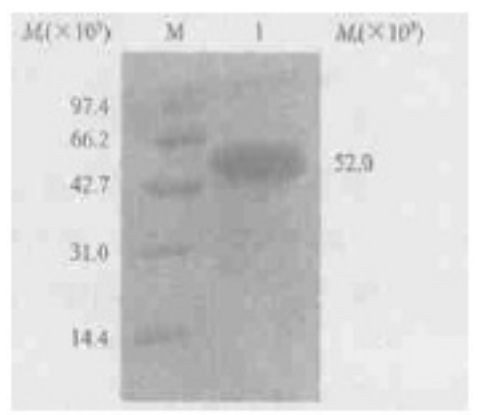

Figure 1. SDS-PAGE of crude flagellin preparation. Lane $M=$ standard protein markers (from upper to lower: rabbit muscle phosphorylase $b$, bovine serum alumin, hen egg white ovalbumin, bovine erythrocyte carbonic anhydrase, chicken egg white lysozyme); lane $1=$ crude flagellin preparation (m.w. $52.0 \times 10^{3}$ ). 


\section{Purification of crude flagellin through the AKTA explorer}

After the crude flagellin protein was sampled into the desalination system, the eluted protein was collected when the first protein peak emerged according to the system settings (mainly flagellin). The protein was sampled again after the salt peak outflow until the desalination process was completed (Figure 2). After desalination, the protein solution was concentrated and purified by weak anion exchange chromatography. The eluted protein was collected when the protein peak emerged according to the system settings for flagellin (Figure 3). The purified flagellin protein was freeze-dried and preserved at $-70^{\circ} \mathrm{C}$.

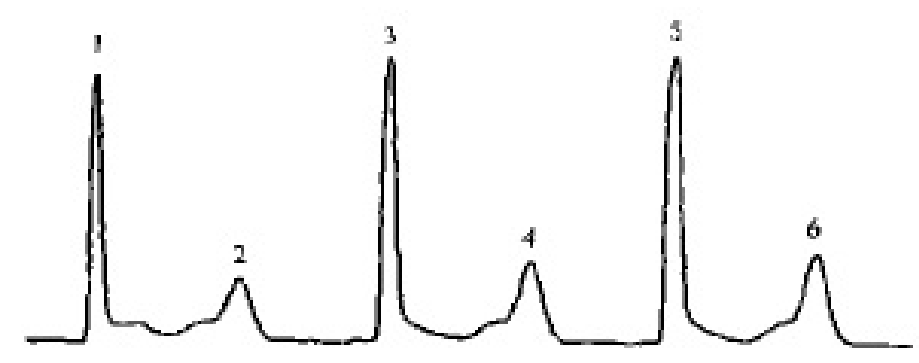

Figure 2. Peak of protein and salt in desalination. Peaks 1, 3, 5= protein; peaks 2, 4, $6=$ salt.

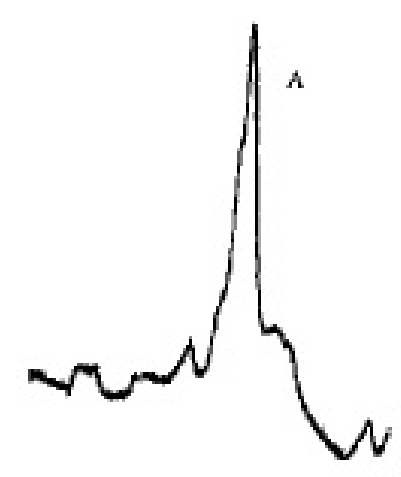

Figure 3. Peak of protein in ion exchange chromatography. Peak $A=$ protein.

\section{SDS-PAGE, Western blot, and SEM radiography analysis}

The purified product was confirmed to be flagellin. The SDS-PAGE assay and gel imaging system analysis showed that the purified protein product had only one protein band at $52 \times 10^{3}$ m.w., as shown in Figure 4. Western blot analysis showed that the reaction product of purified protein product and the anti-Munich S. typhi flagellin monoclonal antibody had a single band at $52 \times 10^{3} \mathrm{~m} . \mathrm{w}$. (Figure 5). After negative staining with phosphotungstic acid, the SEM results showed that the purified protein was filamentous, indicating that the filament substance was indeed flagellin (Figure 6). 


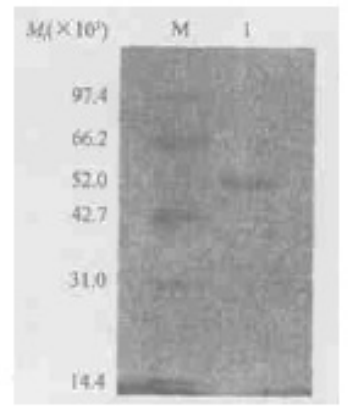

Figure 4. SDS-PAGE of purified flagellin. Lane $M=$ standard protein markers (from upper to lower: rabbit muscle phosphorylase b, bovine serum alumin, hen egg white ovalbumin, bovine erythrocyte carbonic anhydrase, chicken egg white lysozyme); lane 1 = purified flagellin $\left(\right.$ Mr $\left.52.0 \times 10^{3}\right)$.

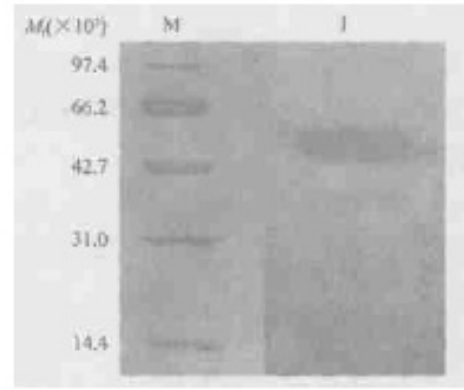

Figure 5. Western blot of purified flagellin. Lane $M=$ standard protein markers (from upper to lower: rabbit muscle phosphorylase $\mathrm{b}$, bovine serum alumin, hen egg white ovalbumin, bovine erythrocyte carbonic anhydrase, chicken egg white lysozyme); lane 1 = purified flagellin $\left(\mathrm{Mr} 52.0 \times 10^{3}\right)$. Lane 1 was reacted with a 1:2000 dilution of the monoclonal antibody to flagellin of Salmonella muenchen.

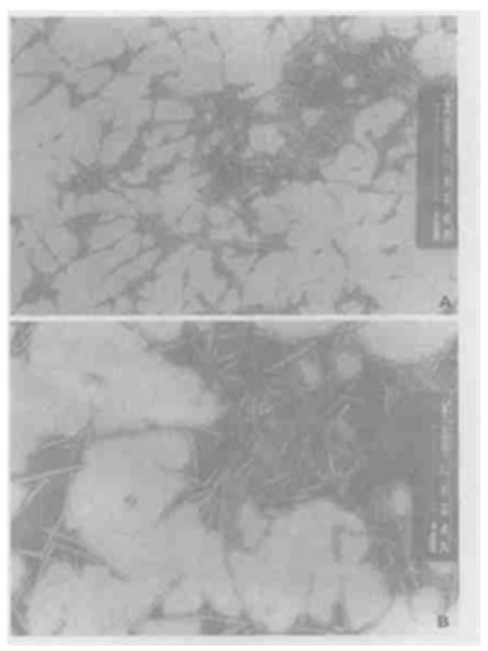

Figure 6. Photograph of scanning electron microscopy (SEM) of the purified flagellin. The purified flagellin with phosphotungstic acid negative staining was filaceous in SEM. A. 20,000X; B. 30,000X. 


\section{Quantification of flagellin}

For every $1 \mathrm{~g}$ wet weight $S$. paratyphi A, $8 \pm 0.5 \mathrm{mg}$ flagellin could be obtained.

\section{Identification and titer determination of rabbit anti-flagellin antiserum}

Western blotting analysis showed that the purified protein product could react with flagellin antiserum, and a single band was located at $52 \times 10^{3} \mathrm{~m} . \mathrm{w}$., indicating that the flagellin antiserum preparation was successful (Figure 7).

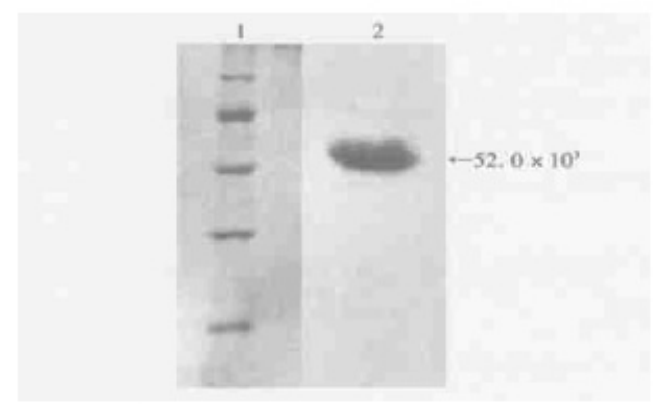

Figure 7. Western-blotting results of flagellin protein antiserum. Lane $1=$ marker; lane 2 = purified flagellin, reacted with 1:10 dilution of the anti-serum to flagellin.

\section{DISCUSSION}

Flagellin is the structural protein (i.e., $\mathrm{H}$ antigens) of the filamentous portion of Salmonella flagella (including the base portion, the hook portion, and the filamentous portion), with a m.w. of $40-60 \times 10^{3}$ (Liaudet et al., 2002, 2003). In recent years, studies have shown that flagellin can cause immune responses through the Toll-like receptor. In sepsis, flagellin is a particularly important inflammatory stimulus, which leads to the expression of proinflammatory mediators through monocytes (Ciacci-Woolwine et al., 1998; McDermott et al., 2000; Moors et al., 2001) and intestinal epithelial cells (Eaves-Pyles et al., 2001; Gewirtz et al., 2001; Mizel et al., 2003; Chabot et al., 2008; Ivison et al., 2010, 2011; Carvalho et al., $2012 a, b)$. Therefore, it is very necessary to study the role of flagellin. Before this can be accomplished, however, its purified product must first be obtained. In contrast to other methods of extracting flagellin, our method is simple and direct, and requires only 3 days to obtain crude flagellin with relatively high purity. SDS-PAGE analysis showed only a single band, indicating high purity of the extracted crude flagellin, which was almost completely free of other proteins. In order to improve the production of flagellin, researchers generally increase the protein quantity of the medium, which results in difficulties for protein purification, particularly when the components of the medium have an m.w. that is similar to that of flagellin, making it difficult or even impossible to effectively purify the protein. Some researchers have used the mechanical milling method to detach flagellin from the cell, which results in O antigen shedding, cell fracturing, and protein release, thus increasing the difficulty of purification. Heat production in the process of the ultrasonic method causes protein denaturation (Fey and 
Wetzstein, 1975), resulting in changes of the protein's physicochemical properties and biological activity. Therefore, we here used a simple procedure to improve the medium and methods of bacterial lysis: the protein was substituted by amino acids in the medium, and flagellin was detached from cells under different $\mathrm{pH}$ conditions. Using the improved method, the crude flagellin obtained had relatively high purity. These results demonstrated that the purification process is relatively easy, making it easier to obtain a high yield of flagellin, thereby reducing the cost and time required.

The nutrients of the medium used in the acid lysis method were all substances of low molecular weight, which could all be cleared under different $\mathrm{pH}$ conditions at different centrifugal speeds. Almost all of the obtained crude flagellin was located at the $52 \times 10^{3} \mathrm{~m} . \mathrm{w}$. position, which confirmed that the relatively pure protein could be obtained with this method.

For in-depth studies of flagellin, a high purity product is required under certain circumstances, such as in the production of flagellin-induced animal ALI models. When preparing the flagellin antibody with immunized animals, further purification is needed to obtain high purity product in order to exclude the impact of other components in the crude protein. When purifying the protein, we used the AKTA Explorer system, an automated protein purification system that was quick and easy to use. The isoelectric point (pI) of $S$. paratyphi A flagellin is around 4.9, and is a negatively charged protein; therefore, we used a weak anion exchange column. The choice of ion exchange conditions and salt gradient are key factors that affect the purification of the protein. In weak ion exchange, the $\mathrm{pH}$ of the balance solution and the sample should be higher than the $\mathrm{pI}$ value by one or more units, and the salt concentration should preferably be between 20-50 mM. Therefore, we here used $20 \mathrm{mM}$ PBS, pH 6.0, buffer as the balance solution, which enabled the negatively charged target protein to bond well with the positive groups on the ion exchange column. In gradient elution, a common salt gradient, $\mathrm{pH}$ gradient, or both, are commonly used. Since the salt gradient is easy to regulate and is more commonly used, salt gradient elution was used in this experiment, with a gradient of 0 to $100 \%$ completed within 10 column bed volumes. The results showed that under the above conditions, we could obtain a pure target protein by electrophoresis.

The purified protein was identified with SDS-PAGE, Western blot, phosphotungstic acid negative staining, and electron microscopy radiography. SDS-PAGE and Western blot analysis showed purified flagellin protein bands at $52 \times 10^{3} \mathrm{~m} . \mathrm{w}$., and electron microscope radiography showed that the flagellin was filamentous, exhibiting the same morphology as that extracted using other methods. Collectively, these results confirmed that the protein was indeed flagellin and that it was uniform.

It was relatively simple and quick to immunize the New Zealand white rabbits with purified flagellin, taking approximately two months to produce high titer antisera (up to 1:64). The antiserum showed strips located at $52 \times 10^{3} \mathrm{~m} . \mathrm{w}$. in immunoblotting analyses, indicating that there was flagellin antibody in the antiserum and that the flagellin antiserum was successfully prepared.

By using the methods described above, we could quickly obtain a high amount of purified flagellin and quickly immunize New Zealand white rabbits to produce high titer antiserum, which will provide the baseline material for studying flagellin-induced and antagonistic sepsis-induced inflammatory injury.

\section{ACKNOWLEDGMENTS}

Research supported by the National Natural Science Foundation of China (\#30370631). 


\section{REFERENCES}

Carvalho FA, Koren O, Goodrich JK, Johansson ME, et al. (2012a). Transient inability to manage proteobacteria promotes chronic gut inflammation in TLR5-deficient mice. Cell Host Microbe 12: 139-152.

Carvalho FA, Nalbantoglu I, Aitken JD, Uchiyama R, et al. (2012b). Cytosolic flagellin receptor NLRC4 protects mice against mucosal and systemic challenges. Mucosal. Immunol. 5: 288-298.

Chabot SM, Shawi M, Eaves-Pyles T and Neutra MR (2008). Effects of flagellin on the functions of follicle-associated epithelium. J. Infect. Dis. 198: 907-910.

Ciacci-Woolwine F, Blomfield IC, Richardson SH and Mizel SB (1998). Salmonella flagellin induces tumor necrosis factor alpha in a human promonocytic cell line. Infect. Immun. 66: 1127-1134.

Dhokarh R, Li G, Schmickl CN, Kashyap R, et al. (2012). Drug-associated acute lung injury: a population-based cohort study. Chest 142: 845-850.

Eaves-Pyles T, Bu HF, Tan XD, Cong Y, et al. (2011). Luminal-applied flagellin is internalized by polarized intestinal epithelial cells and elicits immune responses via the TLR5 dependent mechanism. PLoS One 6: e24869.

Faezi S, Sattari M, Mahdavi M and Roudkenar MH (2011). Passive immunisation against Pseudomonas aeruginosa recombinant flagellin in an experimental model of burn wound sepsis. Burns 37: 865-872.

Fey H and Wetzstein HP (1975). Production of potent salmonella H antisera by immunization with flagellae, isolated by immunosorption. Med. Microbiol. Immunol. 161: 73-78.

Gewirtz AT, Simon PO Jr, Schmitt CK, Taylor LJ, et al. (2001). Salmonella typhimurium translocates flagellin across intestinal epithelia, inducing a proinflammatory response. J. Clin. Invest. 107: 99-109.

Ivison SM, Wang C, Himmel ME, Sheridan J, et al. (2010). Oxidative stress enhances IL-8 and inhibits CCL20 production from intestinal epithelial cells in response to bacterial flagellin. Am. J. Physiol. Gastrointest. Liver Physiol. 299: G733-G741.

Ivison SM, Himmel ME, Mayer M, Yao Y, et al. (2011). The stress signal extracellular ATP modulates antiflagellin immune responses in intestinal epithelial cells. Inflamm. Bowel Dis. 17: 319-333.

Liaudet L, Deb A, Pacher P, Mabley JG, et al. (2002). The flagellin-TLR5 axis: Therapeutic opportunities. Drug News Perspect. 15: 397-409.

Liaudet L, Szabo C, Evgenov OV, Murthy KG, et al. (2003). Flagellin from gram-negative bacteria is a potent mediator of acute pulmonary inflammation in sepsis. Shock 19: 131-137.

McDermott PF, Ciacci-Woolwine F, Snipes JA and Mizel SB (2000). High-affinity interaction between gram-negative flagellin and a cell surface polypeptide results in human monocyte activation. Infect. Immun. 68: 5525-5529.

Michalska A, Jurczyk AP, Machala W, Szram S, et al. (2009). Pulmonary contusion and acute respiratory distress syndrome (ARDS) as complications of blunt chest trauma. Arch. Med. Sadowej Kryminol. 59: 148-154.

Mizel SB, Honko AN, Moors MA, Smith PS, et al. (2003). Induction of macrophage nitric oxide production by Gramnegative flagellin involves signaling via heteromeric Toll-like receptor 5/Toll-like receptor 4 complexes. J. Immunol. 170: 6217-6223.

Moors MA, Li L and Mizel SB (2001). Activation of interleukin-1 receptor-associated kinase by gram-negative flagellin. Infect. Immun. 69: 4424-4429.

Parsons EC, Hough CL, Seymour CW, Cooke CR, et al. (2011). Red blood cell transfusion and outcomes in patients with acute lung injury, sepsis and shock. Crit. Care 15: R221.

Rodríguez-Moyado H (2011). Acute lung injury as a consequence of blood transfusion. Rev. Med. Inst. Mex. Seguro Soc. 49: 273-280.

Sadowitz B, Roy S, Gatto LA, Habashi N, et al. (2011). Lung injury induced by sepsis: lessons learned from large animal models and future directions for treatment. Expert Rev. Anti Infect. Ther. 9: 1169-1178.

Sambrook J and Russell DW (1989). SDS-Polyacrylamide Gel Electrophoresis of Proteins. Molecular Cloning: A Laboratory Manual. 2nd edn. Cold Spring Harbor Laboratory Press, New York.

Tang XL, Liang XD, Xu RH and Chen ZQ (2011). Preparation of rabbit anti-recombinant human calreticulin antibody and its characterization. Xi Bao Yu Fen. Zi. Mian. Yi Xue Za Zhi. 27: 641-643.

Zhang C, Wu X, Zhao Y, Deng Z, et al. (2011). SIGIRR inhibits toll-like receptor 4, 5, 9-mediated immune responses in human airway epithelial cells. Mol. Biol. Rep. 38: 601-609. 